\title{
Dexamethasone inhibits spontaneous apoptosis in primary cultures of human and rat hepatocytes via $\mathrm{Bcl}-2$ and $\mathrm{Bcl}-\mathrm{xL}$ induction
}

\author{
B Bailly-Maitre ${ }^{1}$, G de Sousa1, K Boulukos ${ }^{2}$, J Gugenheim ${ }^{3}$ \\ and R Rahmani ${ }^{*, 1}$ \\ ${ }^{1}$ Laboratoire de Pharmaco-Toxicologie Cellulaire et Moléculaire, INRA, 06606 \\ Antibes, France \\ 2 Centre de Biochimie, Université de Nice, Faculté des Sciences, 06108 Nice, \\ France \\ ${ }^{3}$ Laboratoire de Chirurgie Expérimentale-Faculté de Medecine, 06107 Nice \\ Cedex 02, France \\ * Corresponding author: $\mathrm{G}$ de Sousa or R Rahmani, Laboratoire de Pharmaco- \\ Toxicologie Cellulaire et Moléculaire, INRA, 06606, Antibes, France. \\ Tel: 334936788 60; Fax: 3346730 40; E-mail: rahmani@antibes.inra.fr.
}

Received 11.10.00; accepted 9.11.00

Edited by A Columbano

\begin{abstract}
We examined the effects of dexamethasone (DEX) on the apoptotic process in primary cultures of human and rat hepatocytes. DEX prolonged cell viability, inhibited the development of an apoptotic morphology, and stabilised the expression of procaspase-3 in both human and rat hepatocytes. In addition, the inhibition of apoptosis by DEX was strongly correlated with a decrease of caspase-3-like protease activity. Moreover, DEX treatment increased the expression of anti-apoptotic Bcl-2 and Bcl-xL proteins in human and rat hepatocytes, respectively, whereas the expression of pro-apoptotic proteins Bcl-xS or Bad was not detected or remained unchanged. The $b c l-x L$ transcript is regulated at the transcriptional level and its expression paralleled that of $\mathrm{Bcl}-\mathrm{xL}$ protein in DEX-treated rat hepatocytes. Taken together, these results indicate that this glucocorticoid exerts a protective role on cell survival and it delays apoptosis of human and rat hepatocytes by modulating caspase-3-like protease activity and bcl-2 and bcl-x gene expression. Cell Death and Differentiation (2001) 8, 279-288.
\end{abstract}

Keywords: cell death; cultured human and rat hepatocytes; caspase-3; Bcl-2 family

Abbreviations: DEX, dexamethasone; FBS, fetal bovine serum; BSA, bovine serum albumin; MTT, 3-(4,5-dimethylthiazol-2-yl)-2,5diphenyl tetrazolium bromide; DMSO, dimethyl sulfoxide; TUNEL, TdT-mediated dUTP Nick End Labelling; PBS, phosphate buffer salin; TdT, Terminal deoxynucleotidyl transferase; dUTP, deoxyuridine triphosphates; DEVD-AFC, N-acetyl-Asp-Glu-Val-Asp-aminotrifluoromethylcoumarin; DTT, dichlorodiphenyltrichloroethane; SDS, sodium dodecyl sulphate; NEG, negative-cells, non-treated cells (-); Control-cells, DMSO-treated cells (+), T0, time zero, time of beginning of treatment; Std, Standards

\section{Introduction}

Apoptosis ${ }^{1}$ is a cellular self-destruction mechanism involved in a variety of biological events such as developmental remodelling, tissue homeostasis, and the removal of unwanted cells ${ }^{2-6}$ in most living tissues, including the mammalian liver. $^{7}$ Like other cells, hepatocytes possess inherent mechanisms for undergoing apoptosis which appear to be as follows: initially various pro-apoptotic signals activate separate signalling pathways, which eventually converge into a common mechanism driven by a unique family of cysteine proteases, called caspases. ${ }^{8-10}$ This mechanism is regulated by several sets of genes, the best characterised of which are the Bcl-2 family. ${ }^{11}$ Disruption or inhibition of the regulation of apoptosis may result in various diseases, including cancer. Thus, the elucidation of mechanisms of apoptosis is of great importance, not only for understanding hepatic carcinogenesis, but also for developing new cancer therapies.

In the normal adult liver, the spontaneous rate of hepatocyte apoptosis is low $(0.05 \%)$ and very rapid $(3 \mathrm{~h})$. These characteristics handicap in vivo studies. ${ }^{12,13}$ Regulation of apoptosis has been studied in hepatoma but there are few studies of spontaneous apoptosis in primary cultures of hepatocytes which are known to die spontaneously, at least in part, by apoptosis with increasing time in culture. ${ }^{14-16}$ Although glucocorticoids induce rapid apoptosis in susceptible thymocyte and lymphocyte populations, several studies have demonstrated the inhibitory effects of glucocorticoids against apoptosis in various models: (i) DEX inhibits spontaneous as well as TNF- $\alpha$-induced human neutrophil apoptosis, ${ }^{17-19}$ (ii) DEX and hydrocortisone abolish tumour necrosis factor $\alpha$ (TNF$\alpha$ )-induced cytoxicity of several tumour cell lines via inhibition of phospholipase $A_{2}$ activity, ${ }^{20,21}$ and (iii) DEX inhibits spontaneous apoptosis and transforming growth factor $\beta_{1}$-induced apoptosis in rat hepatoma cells via $\mathrm{Bcl}-\mathrm{xL}$ induction. ${ }^{22,23}$ However, there appears to be a dual role of glucocorticoids in the regulation of cell death although the mechanism of the anti-apoptotic effects of glucocorticoids has rarely been investigated.

In the present study, we sought to determine whether DEX prevented apoptosis in human and rat hepatocytes through the modulation of apoptosis-associated protein members of the Bcl-2 (Bcl-2, Bcl-xL, Bcl-xS and Bad) and caspase-3 families. We found that DEX delays apoptosis by increasing the expression of $\mathrm{Bcl}-2$ and $\mathrm{Bcl}-\mathrm{xL}$, two anti-apoptotic members of the Bcl-2 family, and by decreasing caspase-3-like activity. This is the first demonstration of the up-regulation of $\mathrm{Bcl}-2$ and $\mathrm{Bcl}-\mathrm{xL}$ by dexamethasone in human and rat primary hepatocytes, respectively. 


\section{Results}

\section{Dexamethasone treatment of human hepatocytes affects morphology and cell viability}

Examination by phase-contrast light microscopy (Figure 1A,B) of human hepatocytes after day 5 of culture revealed that while control hepatocytes (Figure 1A) appeared flattened and irregular in shape, those cultured in the presence of DEX (Figure 1B) were organised as aggregates of well-preserved cells with distinct cell-cell borders. Hepatocytes formed junctional complexes in the areas of contact between neighbouring cells and developed numerous bile canaliculi which are typical features of mature and well-differentiated cells. ${ }^{24-26}$ In the same fields of control cells, few cells appeared to be dying. After day 7 of culture, however, there were visible signs of extensive cell death in control cells (Figure 1C). Numerous dead cells were also seen floating on the surface of the culture although the majority remained attached. On the other hand, in DEX-treated cultures the differentiatedstate was maintained: bile canaliculi were still numerous and the number of dead cells was significantly fewer than in control cultures (Figure 1D). Although the ratio of floating to adherent cells was difficult to quantify, floating cells seemed to be decreased by DEX treatment (data not shown). In addition, the viability of attached cells was confirmed using the MTT assay, a marker of viability. ${ }^{27}$ This assay showed the spontaneous decline in viability of primary monolayers of human untreated (NEG) and DMSO-treated hepatocytes (Figure 2). Viability dropped markedly after day 4 (196 h) until day 9 (216 h) in these cells whereas DEX-treated hepatocytes remained viable for at least day 9. Thus DEX clearly exerts a protective effect for human hepatocyte survival and plays an important role in the preservation of the differentiated phenotype.

\section{Dexamethasone prevents spontaneous hepatocyte apoptosis}

In order to verify whether observed cell death can be ascribed to an apoptotic phenomenon, TUNEL assay ${ }^{28}$ was performed consecutively over a 9-day period in human hepatocytes. As shown in Figure 3, the majority of DMSO-treated hepatocyte nuclei were clearly labelled at day 9 suggesting considerable apoptosis in these cells (Figure 3A), whereas the majority of nuclei from DEX-treated hepatocytes were not (Figure $3 B$ ). The degree of apoptosis varied with the length of time in culture: after day 1, the percentage of apoptotic hepatocytes was low (5\%) in DMSO-treated cells but increased to $17 \%$ at day $2,30 \%$ at day $4,70 \%$ at day 7 and $95 \%$ at day $9(P<0.05)$. Similar results were observed in untreated cells (data not shown). The percentage of TUNEL-positive nuclei in DEXtreated cells was: $1 \%$ at day $1,12 \%$ at day $2,15 \%$ at day $4,28 \%$ at day $7,55 \%$ at day 9 and $95-100 \%$ at day 13 . These results indicate that the proportion of TUNEL-positive nuclei was much greater in DMSO-treated cells than in DEX-treated ones. The number of spontaneously induced apoptotic nuclei was reduced significantly by DEX during the time of experiment. No labelling was observed in control sections incubated in the reaction mixture without TdT (data not shown). Moreover, DNA fragmentation assay gave results consistent with those derived from the MTT assay since detection of fragmented cytoplasmic DNA confirmed a gradual loss of viability from day 3 and continuing until day 9 (data not shown). Therefore, under these culture conditions, an internally encoded suicide program is spontaneously activated in human hepatocyte cultures which can be markedly suppressed by DEX. The rate of cell death by spontaneous apoptosis can be a major determinant of survival for human hepatocytes in culture.

\section{The effects of dexamethasone treatment in inducing hepatocyte cell survival are conserved in both humans and rats}

To determine whether the effects of dexamethasone on hepatocyte survival are specific to human hepatocytes or are more general in affecting hepatocyte survival in other species as well, we performed similar experiments as described above using primary cultures of rat hepatocytes treated with DEX. Interestingly, DEX permitted rat hepatocyte cell survival in a similar fashion to that observed with human hepatocytes based on morphology and cell viability (data not shown). Studies using TUNEL and DNA fragmentation demonstrated that DEX indeed protected rat hepatocytes against apoptosis (Figure 3C,D) confirming that DEX functions in a similar manner in protecting primary cultures of both human and rat hepatocytes against cell death by apoptosis.

\section{Dexamethasone decreases caspase-3-like activity}

Because caspases are the effectors of apoptotic cell death in numerous cell types, we investigated their role in DEXinduced protection of apoptosis. ${ }^{9,29}$ Since intranucleosomal DNA fragmentation was shown to be one consequence of caspase-3 activation in hepatocytes, ${ }^{30}$ the involvement of caspase-3-like rather than caspase-1-like proteases was therefore examined. Measuring DEVD-dependent protease activity provides information concerning the role of caspase-3like proteases. ${ }^{29,31}$ We found that the rate of DEVD-AFC cleavage was much higher in homogenates of control cells than in those of DEX-treated cells after day 9 of culture (Figure 4). In DMSO-treated cells, caspase-3-like protease activity increased significantly at $24 \mathrm{~h}$ (sevenfold over T0), while it remained unchanged in DEX-treated cells under the same conditions (twofold over T0). This peak is most likely due to the stress of seeding primary cells ex vivo, yet does not result in decreased cell viability (Figure 2) probably due to an increase in anti-apoptotic protein expression at $24 \mathrm{~h}$ (Figure 6; see below). A significant second caspase-3-like protease activity peak (fivefold over T0) was observed $120 \mathrm{~h}$ after seeding in control hepatocytes which roughly correlates with an increase in the number of apoptotic nuclei as measured by TUNEL technique. This proteolytic activity progressively decreased until the 9th day $(216 \mathrm{~h})$. Over the same time $(72-216 \mathrm{~h}$, Figure 4$)$, the caspase-3-like protease activity remained unchanged in DEX-treated cells. These results were consistent with those obtained from the TUNEL assay.

We further investigated whether these changes in proteolytic activity correlated with the cleavage of procaspase-3. Indeed, caspases encode proenzyme forms that require proteolytic cleavage for activation (mutual activation). Upon activation, caspases cleave several structural 


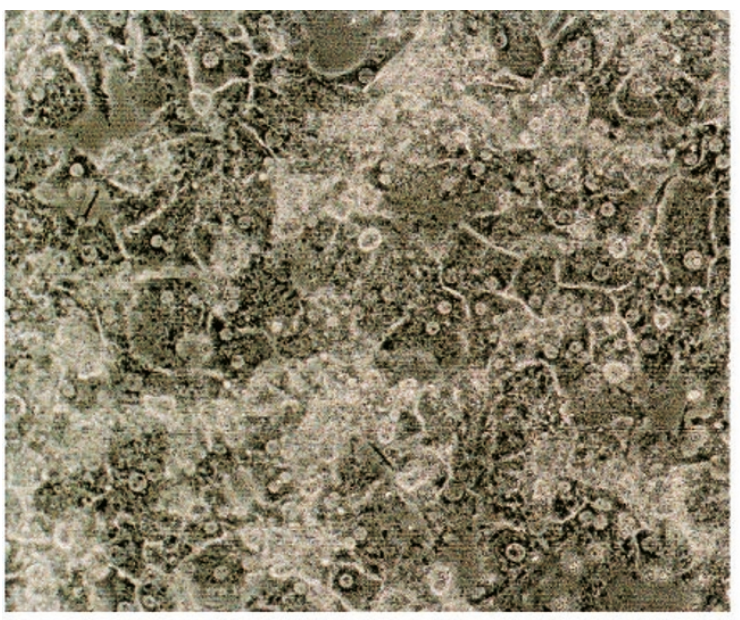

A

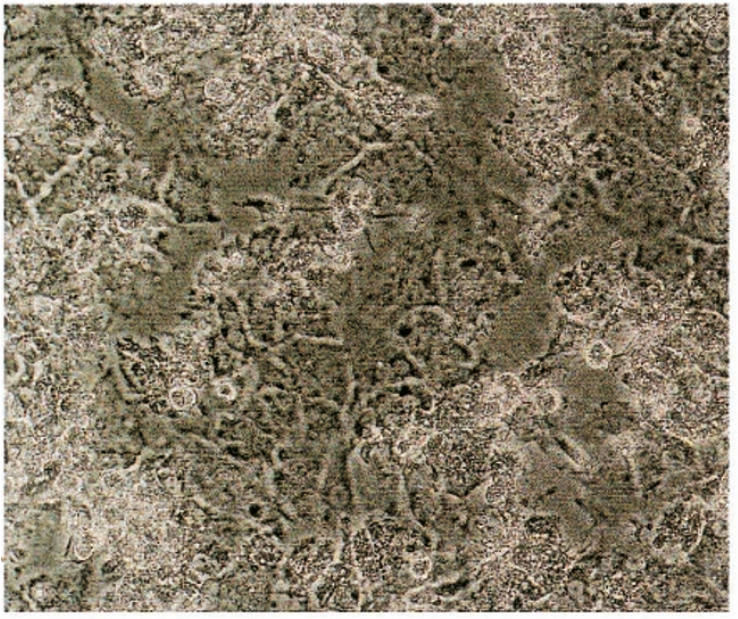

C

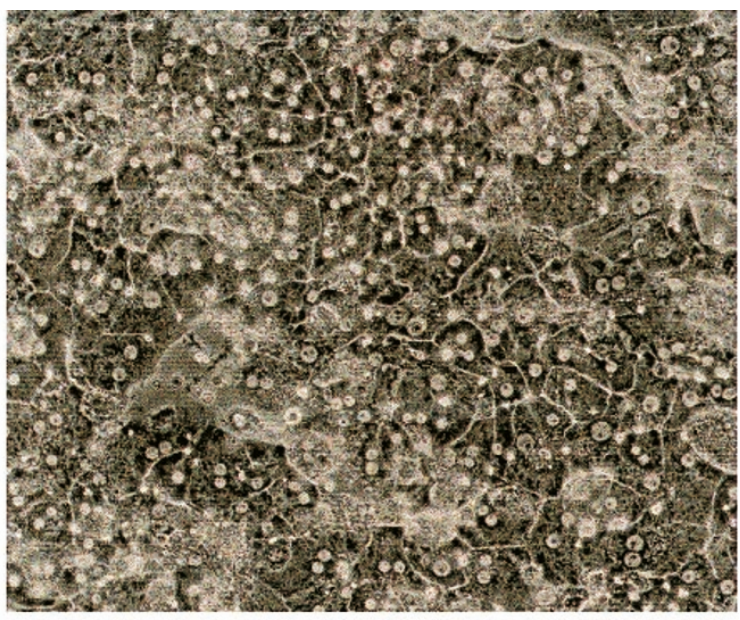

B

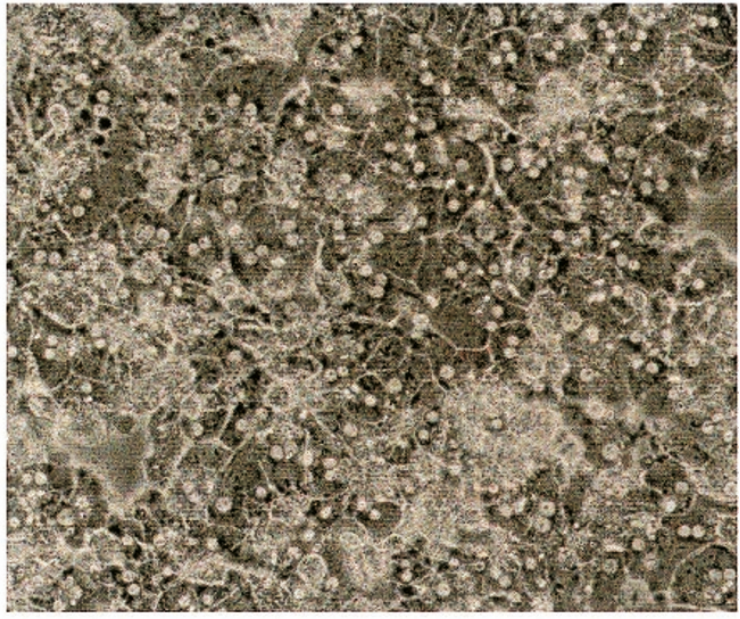

D

Figure 1 Phase-contrast photographs of human hepatocytes treated with or without dexamethasone. (A) and (C) DMSO-treated cells (0.25\%) at days 5 and 7 after seeding. (B, D) Cells after treatment with DEX $(50 \mu \mathrm{M})$ at days 5 and 7 . DEX-treated cells appear better differentiated and form a stable monolayer with polygonal and granular cytoplasm. Plasma and nuclear membranes are also similar to those usually observed in histological preparations of normal hepatic tissues. Finally, bile canaliculi are more numerous. Magnification, $\times 200$

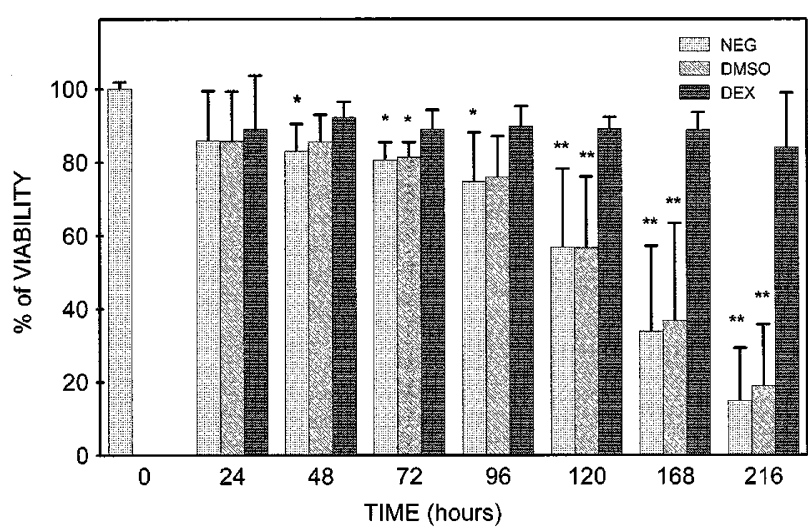

Figure 2 Hepatocyte viability. A MTT assay revealed that human hepatocytes remain viable for at least $216 \mathrm{~h}$ after DEX treatment $(50 \mu \mathrm{M})$. Each value is the mean \pm S.D. of three separate experiments with three replicates. (Note: ${ }^{*} P<0.05$ and ${ }^{* *} P<0.001$. Means \pm S.D.) and catalytic proteins, including proteins involved in the cellular repair system. ${ }^{32,33}$ Examination of the proforms of caspase- 3 by Western blot analysis revealed that spontaneous apoptosis in DMSO-treated hepatocytes paralleled the processing of the procaspase-3 (Figure 5). Thus, a decrease in the level of the zymogene of caspase- 3 was observed. Moreover, in DEX-treated cells, analysis of this zymogene revealed that it was only weakly processed in the presence of DEX. Taken together, our results show that caspase-3-like proteases contribute to spontaneous apoptosis of hepatocytes in primary cultures and that DEX prevents their activation in these experimental conditions.

\section{Effects of dexamethasone on the expression of Bcl-2 family proteins}

To study the effects of DEX on the level of $\mathrm{Bcl}-2$ related proteins, we examined the levels of $\mathrm{Bcl}-2, \mathrm{Bcl}-\mathrm{xL}, \mathrm{Bcl}-\mathrm{xS}$ and 

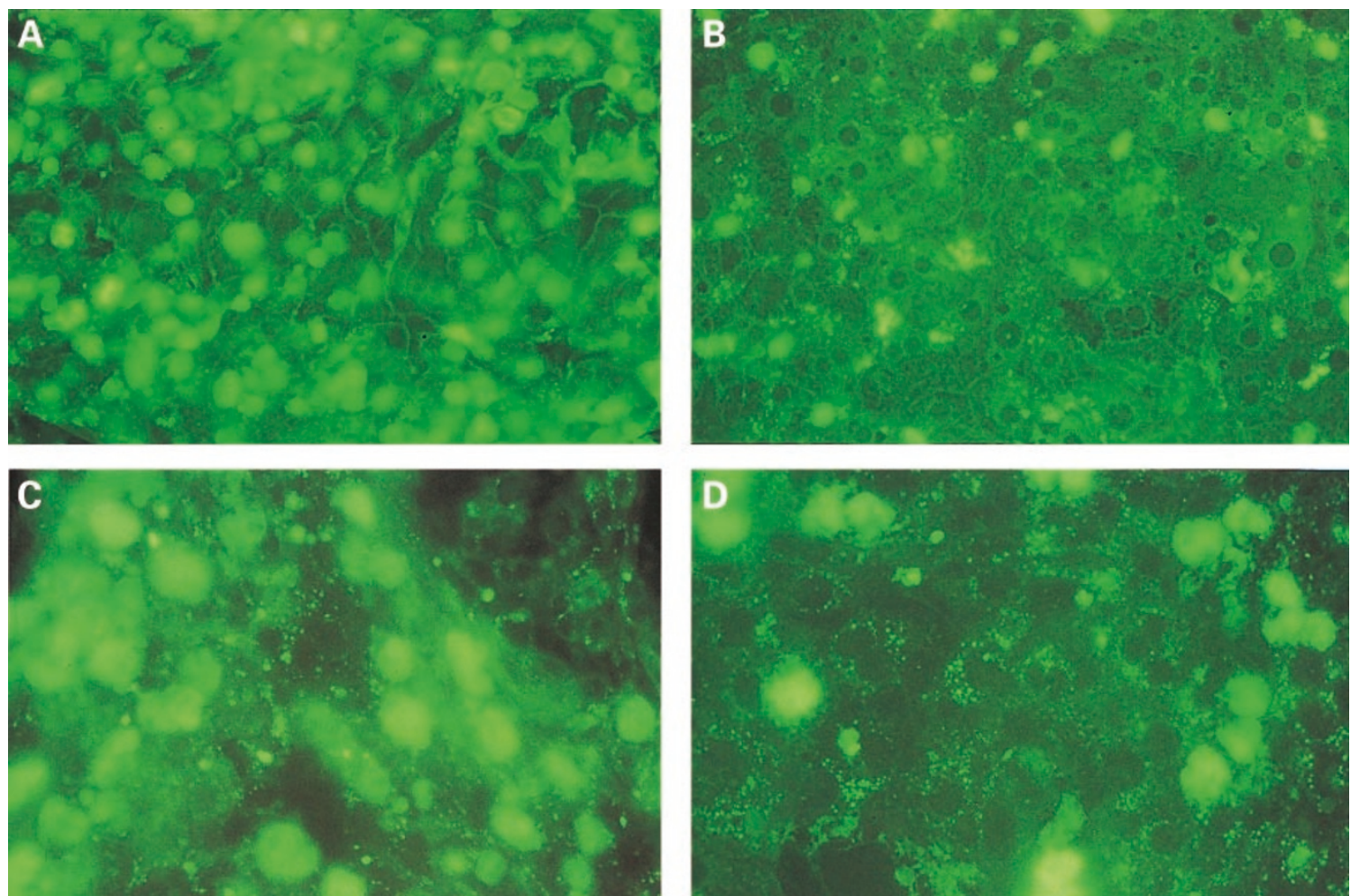

Figure 3 TUNEL assay. Apoptotic human hepatocytes were visualised by end-labeling of 3-OH ends of cleaved DNA fragments using Terminal deoxynucleotidyl Transferase, and fluorescence-labelled nucleotides. The number of apoptotic nuclei (small with condensed chromatin) were counted from representative photographs. Nine days after seeding, TUNEL-positive nuclei (green fluorescence) were twice $(P<0.05)$ as common in control-human hepatocytes $(\mathbf{A})$ than in DEX-treated human ones (B). Similar results were obtained with rat control hepatocytes (C) and DEX-treated rat hepatocytes (D). Data are means \pm S.D. of three separate experiments. Magnification, $\times 650$

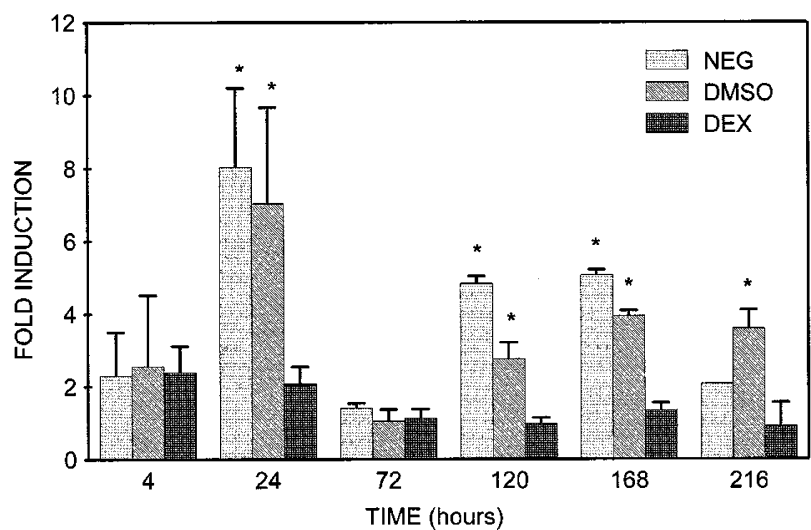

Figure 4 Cleavage of the caspase fluorometric substrate DEVD-AFC in cytosolic extracts of rat hepatocytes. Reaction was monitored every $3 \mathrm{~min}$ for $45 \mathrm{~min}$ by spectrofluorometry. Cleavage of DEVD-AFC is much higher in homogenates of untreated (negative) and control (DMSO $0.25 \%$ ) cells than in those of DEX $(50 \mu \mathrm{M})$ treated ones after $216 \mathrm{~h}$ (day 9) of culture. In DMSO experiments, caspase-3-like protease activity increased significantly at $24 \mathrm{~h}$ (sevenfold over T0), while it remained unchanged in DEX-treated cells after the same time (twofold over T0). An increase of caspase-3-like protease activity was observed in negative and control cells from 5 to 9 days while it decreases progressively from $4 \mathrm{~h}$ to day 9 in DEX treated cells. Fold inductions were calculated with reference to TO (time of beginning of treatments). Similar results were obtained with human hepatocytes. Data are means \pm S.D. of three separate experiments (Note: ${ }^{*} P<0.05$. Means \pm S.D.)

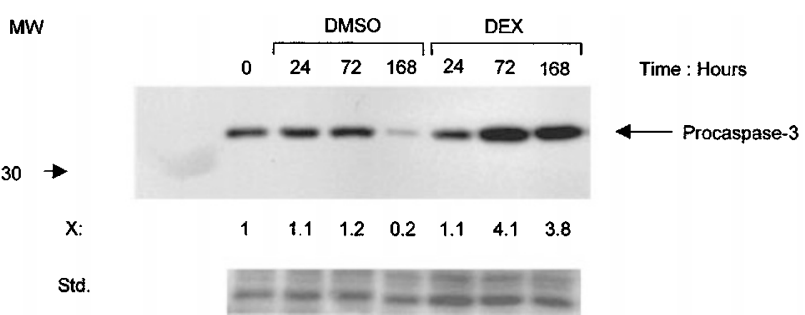

Figure 5 Procaspase- 3 is stabilised by dexamethasone treatment in human hepatocytes. The cells were treated with DMSO $(0.25 \%)$ and DEX $(50 \mu \mathrm{M})$ for 7 days. Equal amounts of cytosolic extract were loaded onto a SDS-12.5\% polyacrylamide gel and transferred to Hybond-P membrane. The blot was then probed with anti-procaspase- 3 antibodies $(50 \mathrm{ng} / \mathrm{ml})$ and processed by ECL as described in Materials and Methods. Fold inductions of procaspase-3, determined by using a densitometer, are given $(\mathrm{X})$, with 1 corresponding to the level of procaspase-3 at T0 (time of beginning of treatments). Std. Ponceau S-stained filter to demonstrate equivalent protein loading and membrane transfert; MW, molecular weight (in $\mathrm{kDa}$ ). The immunoblot shown here represents the typical result from several independent experiments. The same results were obtained in rat hepatocytes

Bad protein expression in the cells by immunoblot analysis. The changes of expression of these proteins are visualised in Figure 6A,B. Anti-apoptotic Bcl-2 protein levels transiently increased in DMSO-treated human hepatocytes. Decreases 


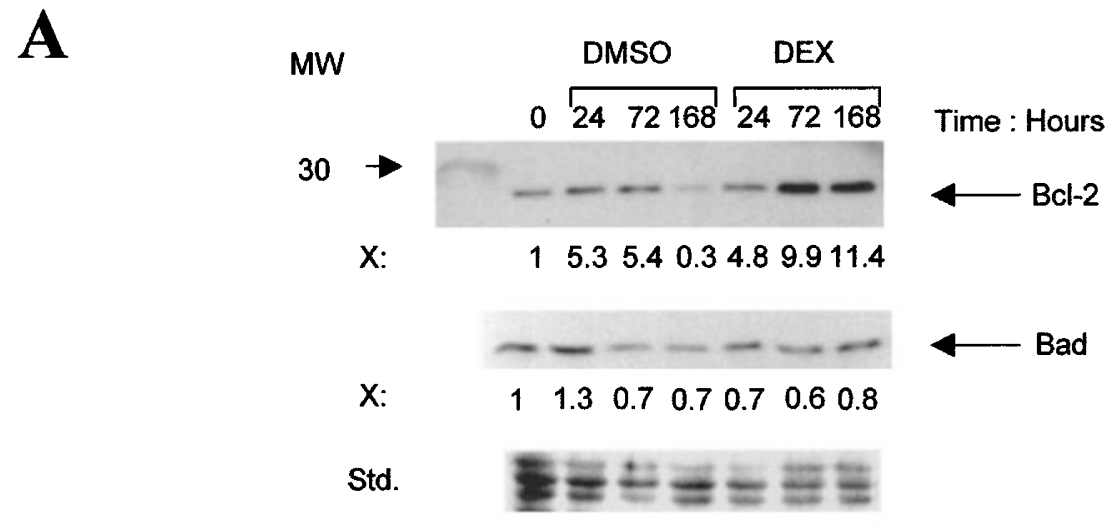

B

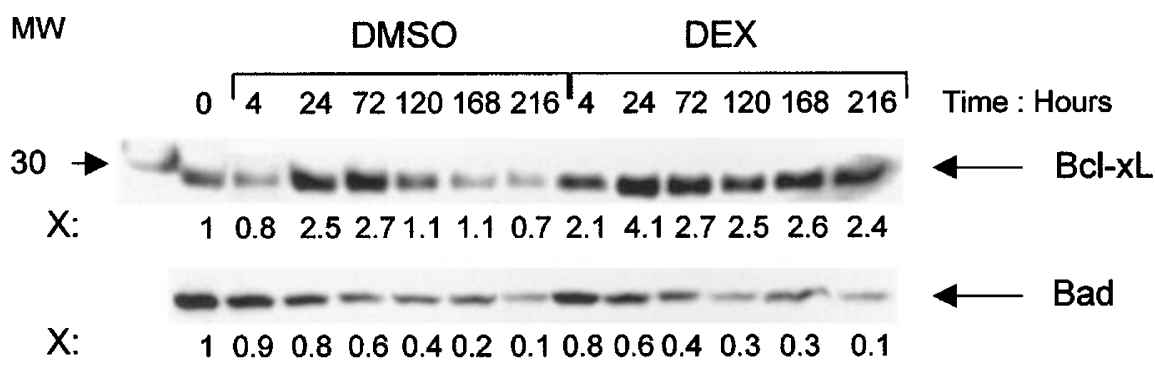

Std.

Figure 6 Western blot analysis of $\mathrm{Bcl}-2, \mathrm{Bcl}-\mathrm{xL}$ and Bad in cultured human $(\mathbf{A})$ and rat $(\mathbf{B})$ hepatocytes. The cells were treated with $\mathrm{DMSO}(0.25 \%)$ and $\mathrm{DEX}$ $(50 \mu \mathrm{M})$ for various lengths of times as indicated. Equal amounts of total protein lysate were loaded onto 10 or $12.5 \%$ SDS-polyacrylamide gels and transferred to Hybond-P membrane. The blots were then probed with anti-Bcl-2 $(50 \mathrm{ng} / \mathrm{ml})$, anti-Bad $(50 \mathrm{ng} / \mathrm{ml})$ and anti-Bcl-x (50 ng/ml) antibodies and processed by $\mathrm{ECL}$ as described in Materials and Methods. (A) Bcl-2 and Bad levels of protein expression in cultured human hepatocytes. (B) Bcl-xL and Bad levels of protein expression in cultured rat hepatocytes. Std. Ponceau S-stained filter to demonstrate equivalent protein loading and membrane transfert; MW, molecular weight (in kDa). Each immunoblot is a representative of three independent experiments that gave similar results. Bcl-2, Bcl-xL and Bad bands were quantified using a densitometer. Fold inductions were determined as described for Figure 5 (Note: ${ }^{\star} P<0.05$. Means \pm S.D.)

in Bcl-2 expression at $168 \mathrm{~h}$ correlate with increased apoptosis and decreased cell viability. In contrast, Bcl-2 protein significantly increased after $72 \mathrm{~h}$ treatment with DEX (twofold over control; $P<0.05$ ) and remained elevated at $168 \mathrm{~h}$ in human hepatocytes (Figure 6A). The level of Bad protein decreased in both control and DEX treated human hepatocytes in a similar fashion (Figure 6A). In rat hepatocytes, $\mathrm{Bcl}-\mathrm{xL}$, and not $\mathrm{Bcl}-2$, is the major anti-apoptotic protein. To determine whether DEX treatment upregulates $\mathrm{Bcl}-\mathrm{xL}$ in rat hepatocytes similarly to the upregulation of $\mathrm{Bcl}-2$ in human hepatocytes; we treated rat hepatocytes with DEX and looked at the level of $\mathrm{Bcl}-\mathrm{xL}$ expression in these cells by Western blot analysis.

Time course analyses showed an increase of the level of $\mathrm{Bcl}-\mathrm{xL}$ at $24 \mathrm{~h}$ in both DMSO and DEX-treated rat hepatocytes (Figure 6B). However by $120 \mathrm{~h}, \mathrm{Bcl}-\mathrm{xL}$ decreased in DMSO-treated cells whereas $\mathrm{Bcl}-\mathrm{XL}$ reached a maximum at $120 \mathrm{~h}$ upon DEX treatment (2.5-fold over control; $P<0.05)$. The $25-\mathrm{kd}$ protein corresponding to $\mathrm{Bcl}-$ $\mathrm{xS}$, an alternatively spliced variant $b c l-x$ gene product with pro-apoptotic activity, was not detected in the immunoblot analysis. Moreover, no specific $\mathrm{Bcl}-2$ immunoreactive bands were detected even though two different commercially available antibodies were used (data not shown).

Together, these results demonstrate that the susceptibilities of human and rat hepatocytes to spontaneous apoptosis were associated with the decreased levels of $\mathrm{Bcl}-$ 2 and $\mathrm{Bcl}-\mathrm{xL}$ in human and rat hepatocytes, respectively. In addition, DEX delayed spontaneous apoptosis in human and rat hepatocytes by increasing the expression of the anti-apoptotic proteins $\mathrm{Bcl}-2$ and $\mathrm{Bcl}-\mathrm{xL}$, respectively.

\section{Effects of dexamethasone on $b c l-2$ and $b c l-x L$ mRNA}

The steady-state mRNA levels of $b c l-2$ and $b c l-x L$ in rat hepatocytes were investigated by Northern blot analysis. As expected from our results obtained by Western blot analyses, $b c l-2$ mRNA levels were very low or undetectable in these cells (data not shown) whereas $b c l-x L$ mRNA levels were readily detectable. The level of $b c l-x L$ mRNA declined rapidly with time in control cells, however, DEX treatment led to an 
increase in the level of $b c l-x L$ mRNA which was still detectable at day 9 (Figure 7). No level of $b c l-x L$ mRNA was detectable in untreated and DMSO-treated cells because the cells are dead. To determine whether the expression of $b c /-x L$ is regulated transcriptionally in rat hepatocytes, the following experiment was performed (Figure 8). Rat hepatocytes were treated with DMSO or DEX for 2 days. Cells were then depleted of DMSO or DEX for $24 \mathrm{~h}$, then restimulated with DMSO or DEX for $2 \mathrm{~h}$ in the presence of actinomycin $\mathrm{D}$ (inhibitor of transcription) or cycloheximide (inhibitor of protein synthesis). Several conclusions can be made: (i) although $\mathrm{bcl}$ $x L$ mRNA is detected in DMSO-treated rat hepatocytes, it is upregulated upon DEX treatment by a factor 2, (ii) treatment with actinomycin $\mathrm{D}$ completely blocks the expression of $b c l-x L$ indicating that $b c l-x L$ has a short half life in these cells, (iii) the increased $b c l-x L$ signal after DEX treatment is completely

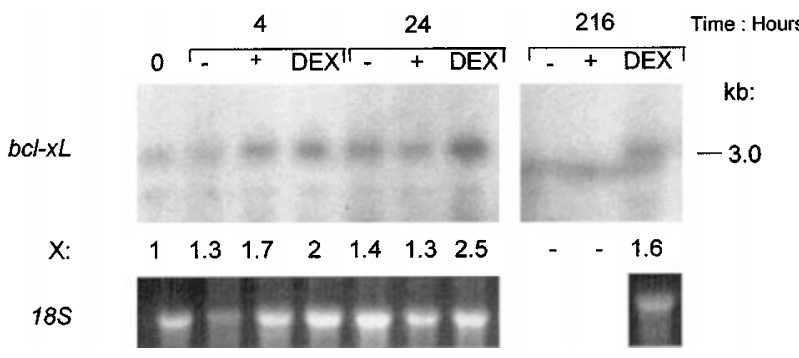

Figure 7 Dexamethasone upregulates the expression of $b c l-x L$ in cultures of rat hepatocytes. RNA was isolated from cells that had been untreated $(-)$ or treated with $0.25 \%$ DMSO (+) or $50 \mu \mathrm{M}$ of dexamethasone (DEX); Ten micrograms of each sample were electrophoresed on a $1 \%$ formaldehyde gel, transferred to a nylon membrane, and hybridised to purified full-length $b c l-x L$, cDNA fragments as probes. The size (in kilobases) of $b c l-x L$ transcript is indicated. Fold inductions of $b c l-x L$ are given $(X)$ by using a densitometer with 1 corresponding to the level of expression of $b c l-x L$ in cells at T0. Ribosoma RNA (18S) was used as loading control. The results are from one experiment, representative of two independent experiments

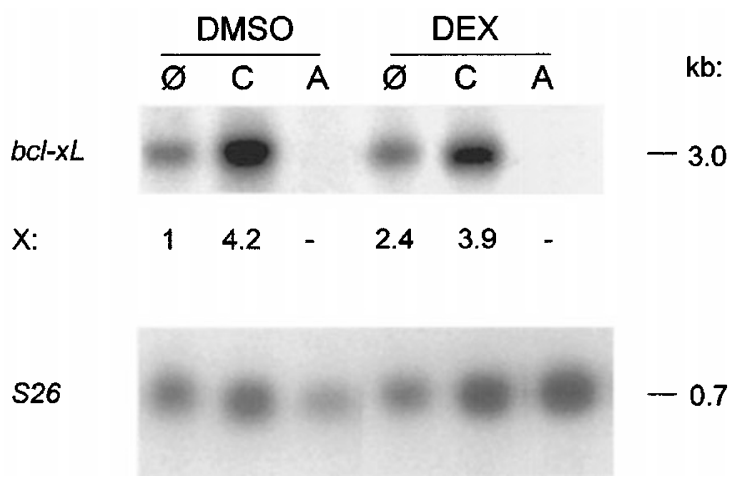

Figure $8 b c l-x L$ upregulation occurs at the transcriptional level in rat hepatocytes. RNA was isolated from rat hepatocytes treated with DMSO or DEX for 2 days. Cells were depleted of DMSO or DEX for $24 \mathrm{~h}(\varnothing)$ then pretreated with cycloheximide $(\mathbf{C})$ or actinomycine $D(\mathbf{A})$, and then maintained alone or treated with DEX for $2 \mathrm{~h}$ as described in Materials and Methods. Ten micrograms of each sample was electrophoresed and hybridised to $b c l-x L$ and S26 cDNA as probes. The size (in kilobases) of each transcript is indicated. The expression of $b c l-x L$ in cells at T0, was arbitrarily set as 1. Fold inductions of $b c l-x L$ are corrected according to $S 26$ ribosomal protein mRNA hybridisation, included as a control for RNA loading ${ }^{60}$ blocked with actinomycin $D$ indicating that increases in $b c l-x L$ mRNA are due to an increase in $b c l-x$ promoter activity, and (iv) cycloheximide stabilises $b c /-x L$ expression similarly in both DMSO or DEX treated hepatocytes indicating that no de novo protein synthesis is necessary for $b c l-x$ transcription (Figure 8). To summarise, these results indicate that the $b c l-x$ gene is regulated transcriptionally upon DEX treatment.

\section{Discussion}

In this study we show that the glucocorticoid dexamethasone (DEX) induces resistance to spontaneous apoptosis in primary cultures of both human and rat hepatocytes indicating that the effects of DEX are not species specific but are general to these cells. These results are corroborated by the findings that DEX inhibits apoptosis by inducing the expression of anti-apoptotic proteins, Bcl-2 and Bcl-xL in human and rat hepatocytes, respectively while the proapoptotic protein Bad remains unchanged. Furthermore, expression of the zymogene of caspase-3 protein was stabilised and caspase-3-like protease activities were significantly reduced in the presence of DEX. By these mechanisms, DEX may be able to inhibit, at least partly, the spontaneous hepatocyte apoptosis which apparently occurs without any particular pro-apoptotic signal.

Glucocorticoids play a fundamental role in normal development and physiological control in animals by modulating the proliferation of various normal and malignant cells. ${ }^{34}$ They are also well known to have antiinflammatory and immunosuppressive properties, ${ }^{35}$ and have been shown to induce irreversible G1 arrest and cell death in a human lymphoblastic leukemic T-cell line (CEMC7). ${ }^{36}$ Some properties of glucocorticoids are a result of direct post-transcriptional effect. The majority, however, are a consequence of effects on gene expression via the glucocorticoid receptor. ${ }^{37,38}$ Clinically, they have been used in the treatment of lymphoid leukemia and lymphoma and the mechanism underlying this treatment is the induction of cell apoptosis. ${ }^{39}$ Thus initially, glucocorticoids were reported to stimulate apoptosis, but inhibitory effects have also been reported. ${ }^{22,23}$

It has been shown that apoptosis occurs in some cell types in vitro in response to various stimuli such as nutrient deprivation and growth factor withdrawal. ${ }^{4}$ In hepatocytes, apoptosis may be induced by a wide variety of stimuli such as TNF- $\alpha$ or Fas stimulation making this model system well adapted to research on programmed cell death. Recently, it has also been shown that spontaneous apoptosis occurs in primary cultures of rat hepatocytes. ${ }^{13,14,16}$

In the present study, we showed that human hepatocytes died spontaneously by apoptosis a few days after seeding and that DEX decreased the susceptibility of hepatocytes to spontaneous apoptosis. It decreased the number of TUNEL positive apoptotic nuclei, delayed DNA fragmentation, and therefore increased hepatocyte survival. These results are in accordance with the finding that glucocorticoid treatment extends the life and inhibits spontaneous apoptosis of human neutrophils. ${ }^{17-19}$ In M1 myeloid leukemic cells and human mammary epithelial cells, treatment with glucocorticoids also results in a decrease in the susceptibility of the 
cells to apoptosis-inducing agents. ${ }^{40,41}$ As in neutrophils and leukemic cells, ${ }^{36,41}$ however, we found that DEX delayed, rather than blocked apoptosis, thereby prolonging hepatocyte survival.

The susceptibility of hepatocytes to apoptosis in primarycultures appears to be due to the downregulation of $\mathrm{Bcl}-2$ and $\mathrm{Bcl}-\mathrm{xL}$ proteins in these cells. Indeed, the products of the $b c l-2$ gene family regulate conserved cellular pathways in various cells in response to a variety of apoptotic stimuli. $\mathrm{Bcl}-2$ and $\mathrm{Bcl}-\mathrm{xL}$ are two closely related members of the $\mathrm{Bcl}-2$ family which inhibit apoptosis. Their genomic structures are quite similar suggesting that these two genes arised from a common ancestor or by gene duplication. ${ }^{42}$ It has been shown that overexpression of these proteins prevents a wide variety of cells from undergoing apoptosis induced by apoptotic stimuli. ${ }^{11,43-46}$ On the other hand, pro-apoptotic members of this family such as Bad, or Bcl-xS counteract the survival-promoting effect of Bcl-2 and Bcl-xL. ${ }^{11,45,47-49}$ In this study, anti-Bcl-x antibody detected only the 30-kd Bcl-xL form, while the 25kd Bcl-xS form was not detectable. Treatment by DEX inhibited the downregulation of endogenous $\mathrm{Bcl}-2$ and $\mathrm{Bcl}-$ $\mathrm{xL}$ proteins in human and rat hepatocytes respectively. $\mathrm{Bcl}-$ $\mathrm{xL}$ could not be detected in human hepatocytes while Bcl-2 was undetectable in those of the rat. Moreover, Bad levels did not change after DEX treatment. The ratios of pro- to anti-apoptotic Bcl-2 family proteins determine the ultimate sensitivity or resistance of cells to apoptotic signals. It appears that in addition to inhibiting caspase-3-like protease activity, the regulation of the $\mathrm{Bcl}-2$ and $\mathrm{Bcl}-\mathrm{xL}$ levels by $\mathrm{DEX}$ and perhaps other stimuli is the main factor inhibiting apoptosis in our hepatocyte model. Since the increased expression of $\mathrm{Bcl}-2$ and $\mathrm{Bcl}-\mathrm{xL}$ was shown to be associated with delayed apoptosis, our results demonstrate that the suppression of spontaneous apoptosis by DEX is mediated by the induction of $\mathrm{Bcl}-2$ and $\mathrm{Bcl}-\mathrm{xL}$ expression. Qiao et $\mathrm{al}{ }^{16}$ have demonstrated that Bax may be an important protein for cell density and matrix-dependent regulation of apoptosis in cultured rat hepatocytes, whereas the $\mathrm{Bcl}-2$ expression observed in cultures appeared unrelated to the rate of apoptosis. The related apoptosis-regulating genes, $b c /-2$, $b c l-x$, and $b a d$, may be independently regulated, and the particular combination of Bcl-2 family proteins would act as a key regulator of apoptosis (depending on cell-types).

In control rat hepatocytes the $b c /-x L$ transcript is upregulated when de novo protein synthesis is prevented and is absent in the presence of an inhibitor of transcription in agreement with results previously reported using macrophages. ${ }^{50}$ In addition, the upregulation of $b c l-x L$ mRNA expression by DEX treatment was completely inhibited in the presence of actinomycin $D$ indicating an increase in $b c l-x L$ expression is due to an increase in $b c l-x$ promoter activity. The increases in steady-state $b c l-x L$ mRNA levels found in DEX treated rat hepatocytes are consistent with the increased expression of $\mathrm{Bcl}-\mathrm{xL}$ proteins in these cells. The enhanced $b c l-x L$ mRNA and protein levels in rat hepatocytes appear to represent a part of the mechanism underlying the protective effect of DEX. Chang et $a l,{ }^{51}$ showed that the expression of the $b c l-x$ gene in TMK1 cells is regulated by DEX at both posttranscriptional and translational levels. Our results indicate that transcriptional mechanisms are important. Stabilisation of mRNA transcripts is common for various genes which are regulated by glucocorticoids. Suppression of susceptibility to spontaneous apoptosis in rat hepatocytes in primary culture was shown to be associated with an enhanced steady-state level of $b c l-x L$ mRNA. In conclusion, the expression of the $b c /-x$ gene in rat hepatocytes appears to be regulated at transcriptional, posttranscriptional and translational levels by dexamethasone. The results presented in this study indicate that modulation of $b c /-x$ gene expression is related to the susceptibility of hepatocytes to apoptosis. The antiapoptotic effects of dexamethasone in cells such as hepatocytes may thus be related to the modulation of $b c l-x$ gene expression.

Although, the $\mathrm{Bcl}-2$ and caspase families have received much attention, the relationship of these families to mechanisms of interaction at the molecular level is still unclear. Activation of the proteolytic caspase cascade has been identified as the final common pathway of apoptosis in diverse biological systems. Kim et $\mathrm{al}^{14}{ }^{14}$ demonstrated the strict correlation between the extent of cell death and activation of caspase-3-like protease in rat hepatocytes. At $24 \mathrm{~h}$, because of the stress of isolation and seeding of hepatocytes, our results showed a strong increase in caspase-3-like protease activity of control cells while it is unchanged in DEX treated cells. This indicates that the effect of DEX in preventing caspase-3 like activity starts before $24 \mathrm{~h}$. Surprisingly, in parallel, no decrease can be seen in the level of the procaspase-3. It is known that while caspase-3 is often the primary source of cellular 'DEVDase' activity, other 'effector' caspases, such as caspase-7 and caspase- 6 may also contribute. ${ }^{52}$ Therefore, our results indicate that these other caspases might be preferentially activated after seeding, and for this reason, no decrease in the level of procaspase-3 was observed. Moreover, no decrease of the viability can be seen at this time. It is known that caspase activation does not systematically result in cell death. ${ }^{53,54}$ For example, Kennedy et $a l^{54}$ have shown the requirement of caspase activation for $\mathrm{T}$ cell proliferation. Our results showed that stabilisation of the procaspase- 3 protein is strongly correlated with a decrease of caspase-3-like activity in the presence of DEX. Consequently, the antiapoptotic effects of DEX would appear to converge upstream of the activation of caspase-3 or related caspases.

Taken together, these results show that the antiapoptotic effects of DEX in hepatocytes are linked to the modulation of the expression of the related genes $b c l-2$, $b c l-x L$, and caspase- 3 which can be diversely regulated. They suggest that spontaneous apoptosis in hepatocytes is controlled by the balance between expression of these and possibly other apoptosis-inducing or -suppressing genes.

\section{Materials and Methods}

\section{Chemicals}

Williams' medium E, foetal bovine serum (FBS), and agarose 1000 were obtained from Gibco BRL (Life Technologies, Paisley, UK) and 
penicillin/streptomycin solution from Bio-Whittaker (CAMBREX Company, Walkersville, USA). Collagenase and guanidine thiocyanate were from Boehringer Mannheim (Mannheim Corp; Sydney, Australia), insulin from Nova Nordisk (Nova Nordisk A/S, Bagsvaerd, Denmark) and RiboGreen and Bodipy FL-14-dUTP from Molecular Probes (Eugene, Oregon, USA). All other chemicals were from SigmaAldrich (St.Louis, MO, USA) unless otherwise specified.

\section{Cellular models}

Hepatocytes from human surgical liver biopsies (resected from secondary tumours) and from rat liver were isolated by a two-step collagenase procedure. ${ }^{55}$ Isolated cells were resuspended in medium I consisting of Williams' medium E with $10 \%$ FBS, penicillin $(50 \mathrm{UI} / \mathrm{ml})$, streptomycin $(50 \mu \mathrm{g} / \mathrm{ml})$ and insulin $(0.1 \mathrm{Ul} / \mathrm{ml})$.

Hepatocyte viability was determined by the Erythrosin B exclusion test, and was at least $80 \%$. Hepatocytes were seeded in collagen type I-coated dishes and incubated $4 \mathrm{~h}$ at $37^{\circ} \mathrm{C}$ in a humidified atmosphere with $95 \%$ air and $5 \% \mathrm{CO}_{2}$. Afterwards, the medium was renewed with medium II which was identical to the first except that it did not contain serum and was supplemented with hydrocortisone hemissucinate $(1 \mu \mathrm{M})$ and bovine serum albumin $(240 \mu \mathrm{g} / \mathrm{ml})$ with or without dexamethasone $(50 \mu \mathrm{M})$.

\section{Cell treatment}

Human and rat hepatocytes were seeded (100 000 cells/well) on 48 well plates (MTT test) and $60 \mathrm{~mm}$ Petri dishes (caspase activities, Western blot, Northern blot, $\left[2.2 \times 10^{6}\right.$ cells per plate]). Hepatocytes were treated over a 9-day period (one treatment every $24 \mathrm{~h}$ ) with $50 \mu \mathrm{M} \mathrm{DEX},{ }^{56,57}$ which was prepared as a dimethylsulfoxide (DMSO) stock solution and was added directly to cultures when changing the culture medium. The final DMSO concentration never exceeded $0.25 \%$ $(\mathrm{v} / \mathrm{v})$.

\section{MTT test}

Cell viability was determined by a colorimetric assay ${ }^{27}$ based on the ability of viable cells, but not dead cells, to reduce $3-(4,5-$ dimethylthiazol-2-yl)-2,5-diphenyl tetrazolium bromide (MTT). This reaction generates a dark blue formazan product. MTT, dissolved in Williams' medium E at $0.5 \mathrm{mg} / \mathrm{ml}$, was added to each well of the plate, then the plate was incubated at $37^{\circ} \mathrm{C}$ for $2 \mathrm{~h}$. The absorbance at $550 \mathrm{~nm}$ was measured using a microplate reader (MR 7000, Dynatech Laboratories, Inc. USA).

\section{TUNEL assay}

The cells were cultured on 13-mm glass coverslips in 24-well plates (seeding density, 200000 cells/well). After various periods, the coverslips containing the cultures were removed, fixed for $30 \mathrm{~min}$ in $4 \%$ paraformaldehyde at room temperature, and permeabilised in PBS $0.1 \%$ Triton $X-100$ and $0.1 \%$ sodium citrate for 2 min on ice. After thorough washing, the coverslips were incubated in a humidified chamber with the TUNEL reaction mixture containing $0.4 \mathrm{UI} / \mu \mathrm{l} \mathrm{TdT}$, $2.5 \mathrm{mM} \mathrm{CoCl}_{2}$ and $2 \mu \mathrm{M}$ Bodipy FL-14-dUTP (TUNEL method, modified from Gavrieli et $a l^{28}$ ). After $60 \mathrm{~min}$ at $37^{\circ} \mathrm{C}$, they were well washed in PBS, mounted in 'antifade' medium, and analyzed under a fluorescence microscope. Negative control coverslips were incubated in the reaction mixture without TdT whereas DNAse $(1 \mu \mathrm{g} / \mathrm{ml})$ was added to coverslips as positive controls before application of the TUNEL reaction mixture. Four fields were randomly selected on each coverslip and the numbers of TUNEL-negative and -positive nuclei counted (a total of 100-150 nuclei were assessed in each field). The number of apoptotic cells was expressed as a percentage of the total nuclei counted.

\section{Caspase activity measurement}

The caspase-3-like protease activity in cell lysates was measured using a fluorometric probe Ac-DEVD-AFC (Alexis Corporation, San Diego, USA), which was dissolved in DMSO and stored as a $10 \mathrm{mM}$ solution at $-20^{\circ} \mathrm{C} .{ }^{31}$ Cells were treated as indicated above. At the end of treatment the Petri dishes were placed on ice and the cells scraped and resuspended in buffer $\mathrm{A}$ (25 mM HEPES $\mathrm{pH} 7.5,5 \mathrm{mM} \mathrm{MgCl}_{2}$, $5 \mathrm{mM}$ EDTA, $5 \mathrm{mM}$ DTT, $2 \mathrm{mM}$ PMSF, $10 \mu \mathrm{g} / \mathrm{ml}$ leupeptin, $10 \mu \mathrm{g} / \mathrm{ml}$ pepstatin A). Cells were lysed by subjecting them to four cycles of freezing and thawing. Homogenates were centrifuged at 14000 r.p.m. for $20 \mathrm{~min}$ and the protein concentrations of the supernatants were determined by the BCA Protein Assay Kit (Pierce, Rockford, Illinois USA). Equal amounts of supernatants were mixed in a microtiter plate

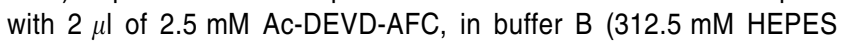
$\mathrm{pH} 7.5,31.25 \%$ sucrose, $0.31 \%$ CHAPS). The fluorometric assay detects the shift in fluorescence emission of AFC after cleavage from DEVD-AFC as measured in a fluorometer $\left(\lambda_{\mathrm{ex}}=390 \mathrm{~nm} ; \lambda_{\mathrm{em}}=530 \mathrm{~nm}\right.$ [Fluorolite 1000, Dynatech Laboratores]). In order to calculate caspase-3-like protease specific activity, the fluorescence value obtained in the presence of the specific inhibitor was subtracted from that in the absence of inhibitor. ${ }^{29}$

\section{Western blot analysis}

Hepatocytes were lysed in RIPA buffer supplemented with $0.1 \%$ SDS. Protein concentration was estimated by the BCA Protein Assay Kit, ${ }^{58}$ using BSA as the standard. Fifty micrograms of total protein were loaded onto 10 or $12.5 \%$ SDS-polyacrylamide gels and electrophoretically transferred onto PVDF membranes (Amersham Life Science, Buckinghamshire, UK). After blocking with $6 \%$ non-fat skim milk in TTBS (10 mmol/L Tris-HCL [pH 7.5], $140 \mathrm{mmol} / \mathrm{L} \mathrm{NaCl}, 0.05 \%$ Tween 20) for $1 \mathrm{~h}$ at $37^{\circ} \mathrm{C}$, the membrane was incubated with primary antibody in TTBS containing 3\% BSA and then washed with TTBS and incubated for $1 \mathrm{~h}$ at room temperature with horseradish peroxidaseconjugated secondary antibodies (anti-mouse immunoglobulin $\mathrm{G}$ or anti-rabbit immunoglobulin G, Promega, Madison, WI, USA). After washing with TTBS, the blot was developed using an $E C L{ }^{\circledR}$ detection kit (Amersham Life Science) and BIOMAX ML film (Eastman Kodak, Rochester, NY, USA). The blot was reprobed with the following antibodies: human and rat monoclonal anti-Bcl-2 antibody (clone 7, Transduction Laboratories, Lexington, KY, USA); rat monoclonal anti$\mathrm{Bcl}-\mathrm{x}$ antibody (clone 4, Transduction Laboratories); human and rat monoclonal anti-Bad antibody (clone 32, Transduction Laboratories); human monoclonal anti-procaspase-3 antibody (clone 19, Transduction Laboratories; rabbit polyclonal anti-rat procaspase-3 antibody (Upstake Biotechnology Inc., Lake Placid, NY, USA). Each band was quantified using a densitometer.

\section{Northern blot analysis}

Rat hepatocytes were treated over a 9 day period with $50 \mu \mathrm{M}$ DEX as indicated in the text. Treatments with actinomycin $D$ and cycloheximide were carried out at 5 and $10 \mu \mathrm{g} / \mathrm{ml}$, respectively. Cells were treated with DMSO or DEX for 2 days. Cells were then depleted of DMSO or DEX for $24 \mathrm{~h}$, then restimulated with DMSO or DEX for $2 \mathrm{~h}$ in the presence of actinomycin $D$ or cycloheximide. The medium was 
removed from 60-mm Petri dishes and the hepatocytes were washed twice with cold PBS before being scraped in $600 \mu \mathrm{l}$ of a guanidium solution (guanidine thiocyanate $4 \mathrm{M}$, sodium citrate $25 \mathrm{mM} \mathrm{pH} \mathrm{7,}$ sarcosyl $0.5 \%$ and 2-mercaptoethanol $0.1 \mathrm{M}^{59}$ The culture extract was kept at $-80^{\circ} \mathrm{C}$ until analysis. Total RNA was isolated using the acidic phenol extraction procedure and quantified with RiboGreen (RNA Quantitation Kit, Molecular Probes). Ten micrograms of total RNA were size-fractionated on a $1.0 \%$ agarose gel containing $1 \%$ formaldehyde, and was then transferred to a nylon membrane (Boehringer) as described by the manufacturer. Purified $b c l-x L, b c l-2$ and S26 CDNA fragments were used as probes. High-specific-activity probes were generated by using the Stratagene Prime-lt kit as described by the manufacturer. Prehybridisation and hybridisation were carried out at $42^{\circ} \mathrm{C}$ in a solution of $6 \times \mathrm{SSC}(1 \times \mathrm{SSC}$ is $0.15 \mathrm{M}$ $\mathrm{NaCl}$ plus $0.015 \mathrm{M}$ sodium citrate) $-5 \times$ Denhardt's solution $-0.5 \%$ sodium dodecyl sulphate (SDS) $-50 \%$ formamide containing $20 \mu \mathrm{g}$ of denatured salmon sperm DNA per $\mathrm{ml}$. Washing was performed under normal-stringency conditions at $50^{\circ} \mathrm{C}$ by using $0.1 \times$ SSC $-0.1 \%$ SDS. All mRNA transcripts were visualised after a 4-12-h exposure to BIOMAX film (Kodak) at $-80^{\circ} \mathrm{C}$ with Dupont Quanta Fast intensifying screens and with a phosphoimager system (Fuji). All signals were quantified by using a densitometer, and fold inductions were calculated by taking into account the S26 signal as a control for RNA loading. ${ }^{60}$

\section{Statistics}

The data are expressed as means \pm standard deviations (S.D.) Statistical significance of differences between various samples was determined by Mann-Whitney U-test. The levels of probability are noted $\left({ }^{*} P<0.05\right.$ or $\left.{ }^{* *} P<0.001\right)$.

\section{Acknowledgements}

We gratefully acknowledge Drs P Auberger and C Delescluse for their advice.

\section{References}

1. Kerr JFR, Wyllie AH and Currie AR (1972) Apoptosis: a basic biological phenomenon with wide-ranging implications in tissue kinetics. Br. J. Cancer 26: 239-257

2. Raff MC (1996) Size control: the regulation of cell numbers in animal development. Cell 86: 173-175

3. Thompson CB (1995) Apoptosis in the pathogenesis and treatment of disease. Science 267: $1456-1462$

4. Reap EA, Leslie D, Abrahams M, Eisenberg RA and Cohen PL (1995) Apoptosis abnormalities of splenic lymphocytes in autoimmune Ipr and gld mice. Immunol. J. 154: $936-943$

5. Liebermann DA, Hoffman B and Steinman RA (1995) Molecular controls of growth arrest and apoptosis: p53-dependent and independent pathway. Oncogene 11: 199-210

6. Melino G, Bernassola F, Knight RA, Corasaniti MT, Nistico G and Finazzi-Agro A (1997) S-nitrosylation regulates apoptosis. Nature 388: 432-433

7. Williams GT, Smith CA, McCartthy NJ and Grimes EA (1992) Apoptosis: final control point in cell biology. Trends Cell Biol. 2: 263-267

8. Alnemri ES, Livingston DJ, Nicholson DW, Salvesen G, Thornberry NA, Wong WW and Yuan J (1996) Human ICE/CED-3 protease nomenclature. Cell 87: 171

9. Thornberry NA and Lazebnick Y (1998) Caspases: enemies within (Review). Science 281: $1312-1316$
10. Slee EA, Harte MT, Kluck RM, Wolf BB, Casiano CA, Newmeyer DD, Wang HG Reed JC, Nicholson DW, Alnemri ES, Green DR and Martin SJ (1999) Ordering the cytochrome c-initiated caspase cascade: hierarchical activation of caspases-2, -3, -6, -7, -8, and -10 in a caspase-9-dependent manner. J. Cell Biol. 144: $281-292$

11. Adams JM and Cory S (1998) The Bcl-2 protein family: arbiters of cell survival (Review). Science 281: $1322-1326$

12. PitotHC (1998) Hepatocytes death in hepatocarcinogenesis. Hepatology $28: 1-$

13. Bursch W, Paffe S, Putz B, Barthel G and Schulte-Hermann R (1990) Determination of the length of the histological stages of apoptosis in normal liver and in altered hepatic foci of rat. Carcinogenesis 11: 847-853

14. Kim YM, Talanian RV and Billiar TR (1997) Nitric oxide protects cultured rat hepatocytes from tumor necrosis factor-alpha-induced apoptosis by inducing heat shock protein 70 expression. J. Biol. Chem. 272: 31138-31148

15. Feldmann G (1997) Liver apoptosis. J Hepatol. 26 (Suppl 2) 1-11

16. Qiao L and Farrell GC (1999) The effects of cell density, attachment substratum and dexamethasone on spontaneous apoptosis of rat hepatocytes in primary culture. In Vitro Cell Dev. Biol. Anim. 35: 417-424

17. Cox G (1995) Glucocorticoid treatment inhibits apoptosis in human neutrophils Separation of survival and activation outcomes. J. Immunol. 154: 4719-4725

18. Liles WC, Dale DC and Klebanoff SJ (1995) Glucocorticoids inhibit apoptosis of human neutrophils. Blood 86: $3181-3188$

19. Kato T, Takeda Y, Nakada T and Sendo F (1995) Inhibition of dexamethasone of human neutrophil apoptosis in vitro. Nat Immun. 4: 198-208

20. Suffys $P$, Beyaert R, De Valck D, Vanhaesebroeck B, Van Roy F and Fiers W (1991) Tumour-necrosis-factor-mediated cytotoxicity is correlated with phospholipase-A2 activity, but not with arachidonic acid release per se. Eur. J. Biochem. 195: 465-475

21. Chang DJ, Ringold GM and Heller RA (1992) Cell killing and induction of manganous superoxide dismutase by tumornecrosis factor-alpha is mediated by lipoxygenase metabolites of arachidonic acid. Biochem. Biophys. Res. Commun. 188: 538-546

22. Chaya D, Fougere-descharette C and Weiss MC (1996) Spontaneous apoptosis in a rat hepatoma cell line and its inhibition by dexamethasone. Cell Death Differ. 3: $97-104$

23. Yamamoto M, Fukuda K, Miura N, Suzuki R, Kodo T and Komatsu Y (1998) Inhibition by dexamethasone of transforming growth factor $\beta 1$-induced apoptosis in rat hepatoma cells: a possible association with $\mathrm{Bcl}-\mathrm{XI}$ induction. Hepatology 959-966

24. Falasca L, Favale A, Gualandi G, Maietta G and Conti Devirgiliis L (1998) Retinoic acid treatment induces apoptosis or expression of a more differentiated phenotype on different fractions of cultured fetal rat hepatocytes. Hepatology 28 : $727-737$

25. Fontaine F, de Sousa G, Burcham PC, Duchene P and Rahmani R. (2000) Role of Cytochromes P450 3A in the metabolism of mefloquine in human and animal hepatocytes. Life Sci 22: 2193-2212

26. Cox RA (1968) In: Enzymology, Vol.12. Grossmann L and Moldave E, (eds). Academic Press, Orlando, FL. pp. 120-129

27. Mossmann T (1983) Rapid colorimetric assay for cellular growth and survival: application to proliferation and cytotoxicity assay. J. Immunol. Methods. 65:5563

28. Gavrieli Y, Sherman Y and Ben-Sasson SA (1992) Identification of programmed cell death in situ via specific labelling of nuclear DNA fragmentation. J. Cell Biol. 119: 493-501

29. Nicholson D and Thornberry N(1997)Caspases: killerproteases. TIBS22:299 306

30. Janicke UR, Sprengart ML, Wati MR and Porter AG (1998) Caspase-3 is required for DNA fragmentation and morphological changes associated with apoptosis. J. Biol. Chem. 273: 9357-9360

31. Gurtu V, Kain SR and Zhang G (1997) Fluorometric and colorimetric detection of caspase activity associated with apoptosis. Anal. Biochem. 251: 98-102

32. Casciola-Rosen L, Nicholson DW, Chong T, Rowan KR, Thornberry NA, Miller DK and Rosen A (1996) Apopain/CPP32 cleave proteins that are essential for cellular repair: a fundamental principle of apoptotic death. J. Exp. Med. 183: $1957-1964$ 
33. Tewari M, Quan LT, O'Rourke K, Desnoyers S, Zeng Z, Beidler DR, Poirier GG, Salvesen GS and Dixit VM (1995) Yama/CPP32 beta, a mammalian homologue of CED-3, is a CrmA-inhibitable protease that cleaves the death substrate poly(ADP-ribose) polymerase. Cell 81: 801-809

34. Tsai MJ and O'Malley BW (1994) Molecular mechanisms of action of steroid/ thyroid receptor superfamily members (Review). Annu. Rev. Biochem. 63: 451486

35. Barnes PJ and Karin M (1997) Nuclear factor-kappaB: a pivotal transcription factor in chronic inflammatory diseases (Review). N. Engl. J. Med. 336: 1066 1071

36. Bansal N, Houle A and Melnykovych G (1991) Apoptosis: mode of cell death induced in T cell leukemia lines by dexamethasone and other agents. FASEB J. 5: $211-216$

37. McEwan IJ, WrightAP and Gustafsson JA (1997) Mechanism of gene expression by the glucocorticoid receptor: role of protein-protein interactions (Review) Bioessays. 19: 153-160

38. Beato M, Herrlich P and Schutz G (1995) Steroid hormone receptors: many actors in search of a plot (Review). Cell 83: 851-857

39. Harmon JM, Norman MR, Fowlkes BJ and Thompson EB (1979) Dexamethasone induces irreversible G1 arrest and death of a human lymphoid cell line. J. Cell. Physiol. 98: 267-278

40. Lotem J and Sachs $L$ (1995) Regulation of bcl-2, bcl-XL and bax in the control of apoptosis by hematopoietic cytokines and dexamethasone. Cell Growth Differ 6: $647-653$

41. Harris RA (1995) The induction of apoptosis in human mammary lumina epithelial cells by expression of activated c-neu and its abrogation by glucocorticoids. Br. J. Cancer 72: 386-392

42. Grillot DA, Gonzalez-Garcia M, Ekhterae D, Duan L, Inohara N, Ohta S, Seldin MF and Nunez G (1997) Genomic organization, promoter region analysis, and chromosome localization of the mouse bcl-x gene. J. Immunol. 158: 4750-4757

43. Jaattela M, Benedict M, Tewari M, Shayman JA and Dixit VM (1995) Bcl-x and Bcl-2 inhibit TNF and Fas-induced apoptosis and activation of phospholipase A2 in breast carcinoma cells. Oncogene 10: 2297-2305

44. Dole MG, Jasty R, Cooper MJ, Thompson CB, Nunez G and Castle VP (1995) $\mathrm{Bcl}-\mathrm{xL}$ is expressed in neuroblastoma cells and modulates chemotherapyinduced apoptosis. Cancer Res. 55: 2576-2582

45. Ibrado AM, Liu L and Bhalla K (1997) Bcl-xL overexpression inhibits progression of molecular events leading to paclitaxel-induced apoptosis of human acute myeloid leukemia HL-60 cells. Cancer Res. 57: 1109-1115

46. White $E$ (1996) Life, death, and the pursuit of apoptosis (Review). Genes Dev. 10: $1-15$
47. Gajewski TF and Thompson CB (1996) Apoptosis meets signal transduction: elimination of a BAD influence. Cell 87: $589-592$

48. Boise LH, Gonzalez-Garcia M, Postema CE, Ding L, Lindsten T, Turka LA, Mao X, Nunez G and Thompson CB (1993) Bcl-x, a bcl-2-related gene that functions as a dominant regulator of apoptotic cell death. Cell 74: 597-608

49. Minn AJ, Boise LH and Thompson CB (1996) Bcl-x(S) antagonises the protective effects of Bcl-x(L). J. Biol. Chem. 271:6306-6312

50. Sevilla L, Aperlo C, Dulic V, Chambard JC, Boutonnet C, Pasquier O, Pognonec $P$ and Boulukos KE (1999) The Ets2 transcription factor inhibits apoptosis induced by CSF-1 deprivation of macrophages through a Bcl-xL-dependent mechanism. Mol. Cell. Biol. 19: 2624-2634

51. Chang TC, Hung MW, Jiang SY, Chu JT, Chu LL and Tsai LC (1997) Dexamethasone suppresses apoptosis in a human gastric cancer cell line through modulation of bcl-x gene expression. FEBS Lett. 415: 11-15

52. Faleiro L, Kobayashi R, Fearnhead H and Lazebnik Y (1997) Multiple species of CPP32 and Mch2 are the major active caspases present in apoptotic cells. EMBO J. 16: 2271-2281

53. Alam A, Cohen LY, Aouad S and Sekaly RP (1999) Early activation of caspases during $T$ lymphocyte stimulation results in selective substrate cleavage in nonapoptotic cells. J. Exp. Med. 190: 1879-1890

54. Kennedy NJ, Kataoka T, Tschoop J and Budd RC (1999) Caspase activation is required for T cell proliferation. J. Exp. Med. 190: 1891-1896

55. Berry MN and Friend DS (1969) High-yield preparation of isolated rat liver parenchymal cells. J. Cell Biol. 43: 506-520

56. Marre F, Sanderink G, de Sousa G, Gaillard C, Martinet MandRahmani R(1996) Hepatic biotransformation of Docetaxel (Taxotere ${ }^{\mathbb{R}}$ ) in vitro: involvement of the CYP3A subfamily in humans. Cancer Res. 56: 1296-1302

57. Rahmani R, de Sousa G, Marre F, Nicolas F and Placidi M (1993) Potential of freshly isolated and cryopreserved human hepatocytes in drug research and development. In Human cells in vitro pharmaco-toxicology Present status within Europe Rogiers V, Sonk W, Shepard E, Vercruysee A, (eds), VUB PRESS, Brussels, $117-138$

58. Smith PK, Krohn RI, Hermanson GT, Mallia AK, Gartner FH, Provenzano MD, Fujimoto EK, Goeke NM, Olson BJ and Klenk DC (1985) Measurement of protein using bicinchoninic acid. Anal. Biochem. 150: 76-85

59. Chomzynski $P$ and Sacchi N (1987) Single step method of RNA isolation by acid guanidinium thiocyanate-phenol-chloroform extraction. Anal. Biochem. 162: $156-159$

60. Vincent S, Marty L and Fort $P$ (1993) S26 ribosomal protein RNA: an invariant control for gene regulation experiments in eukaryotic cells and tissues. Nucleic. Acids Res. 21: 1498 